\title{
Restoration of renal anemia following therapy with etelcalcetide for refractory secondary hyperparathyroidism: a case report with mini-review
}

\author{
Yoshiyuki Oshiro $^{1 *}$, Takumu Nitta ${ }^{2}$ and Masaki Oomoto ${ }^{2}$
}

\begin{abstract}
The patient was a 72-year-old woman who had been under dialysis for a long time to chronic renal failure of unknown etiology. Her dialysis vintage was 22 years. She was under treatment with cinacalcet for secondary hyperparathyroidism (2HPT). However, cinacalcet was withdrawn because she presented digestive complications. In March 2017, treatment with etelcalcetide, a novel intravenous calcimimetic, became possible. On April 10, 2017, her intact parathyroid hormone (PTH) level was $1150 \mathrm{pg} / \mathrm{mL}$, and etelcalcetide $5 \mathrm{mg}$ was administrated three times per week after dialysis. After 6 months, her intact PTH (iPTH) level was $283 \mathrm{pg} / \mathrm{mL}$ and her hemoglobin (Hb) level was $12.9 \mathrm{~g} / \mathrm{dL}$ though she was not administered erythropoietin-stimulating agent (ESA). She had three detectable parathyroid glands. Conventionally, her parathyroid glands should have been removed; however, as her parathyroid hormone level decreased, this procedure was not required. In this patient, etelcalcetide improved severe 2HPT and renal anemia.
\end{abstract}

Keywords: Etelcalcetide, Secondary hyperparathyroidism, Renal anemia

\section{Background}

Secondary hyperparathyroidism (2HPT) is one of the most important complications of chronic renal failure. Elevated concentration of parathyroid hormone causes not only osteitis fibrosa but also various complication including cardiovascular problems. Besides, 2HPT is a cause of erythropoietin-stimulating agent (ESA)-resistant anemia [1]. It has been already reported that therapy with vitamin $\mathrm{D}$ and cinacalcet improves renal anemia [2-4]. Etelcalcetide belongs to new class of drugs that target calcium-sensing receptors in the parathyroid glands. Etelcalcetide proved to be not inferior to cinacalcet in reducing serum PTH [5], and we think etelcalcetide is superior to cinacalcet concerning drug compliance as it is meant to be administered intravenously. We report the case of a patient in whom etelcalcetide exerted a strong suppressive effect on $2 \mathrm{HPT}$ and reversed renal anemia.

\footnotetext{
* Correspondence: y-oshiro@med.kawasaki-m.ac.jp

${ }^{1}$ Kawasaki Medical School, General Internal Medicine 3, 2-6-1, Nakasange,

Kita-ku, Okayama 700-8505, Japan

Full list of author information is available at the end of the article
}

\section{Case presentation}

The patient was a 72-year-old woman who had undergone hemodialysis three times per week since 1995 for end-stage renal disease caused by an infectious disease. She had three hypertrophic parathyroid glands. Conventionally, this condition is an indication of parathyroidectomy. However, she did not desire to undergo parathyroidectomy. Therefore, she was treated with injectable vitamin $\mathrm{D}$ and oral cinacalcet. Moreover, the patient was initiated on maxacalcitol at a dose of $5 \mu \mathrm{g}$ three times per week, yet the dose of maxacalcitol could not be increased because the patient showed hypercalcemia.

And cinacalcet had to be withdrawn due to gastrointestinal problem. Laboratory findings immediately before etelcalcetide treatment were as shown in Table 1 . Her parathyroid glands were $1.4 \times 1.2 \times 1.1 \mathrm{~cm}\left(0.97 \mathrm{~cm}^{3}\right)$, $0.7 \times 0.6 \times 0.3 \mathrm{~cm}\left(0.07 \mathrm{~cm}^{3}\right)$, and $0.8 \times 0.7 \times 0.3 \mathrm{~cm}(0.09$ $\mathrm{cm}^{3}$ ) in size. In April 2017, she was started on etelcalcetide $5 \mathrm{mg}$ three times per week. Two months later, the dose of etelcalcetide was increased to $10 \mathrm{mg}$ three times per week. And after 3 months, the dose of maxacalcitol could be increased to $10 \mu \mathrm{g}$ three times per week. After 
Table 1 Laboratory findings immediately before etelcalcetide treatment

\begin{tabular}{l} 
CBC \\
WBC $4700 / \mu \mathrm{L}$ \\
RBC $448 \times 104 / \mu \mathrm{L}$ \\
Hb $13.3 \mathrm{~g} / \mathrm{dL}$ \\
Ht $41.4 \%$ \\
Plat $15.8 \times 104 / \mu \mathrm{L}$ \\
Blood chemistry \\
AST $10 \mathrm{U} / \mathrm{L}$ \\
ALT $7 \mathrm{U} / \mathrm{L}$ \\
LDH $187 \mathrm{U} / \mathrm{L}$ \\
ALP $314 \mathrm{U} / \mathrm{L}$ \\
Г-GTP $8 \mathrm{U} / \mathrm{L}$ \\
TP $5.8 \mathrm{~g} / \mathrm{dL}$ \\
Alb $3.3 \mathrm{~g} / \mathrm{dL}$ \\
Glob $2.5 \mathrm{~g} / \mathrm{dL}$ \\
Cr $8.79 \mathrm{mg} / \mathrm{dL}$ \\
BUN $76 \mathrm{mg} / \mathrm{dL}$ \\
UA $6.7 \mathrm{mg} / \mathrm{dL}$ \\
Tcho $181 \mathrm{mg} / \mathrm{dL}$ \\
Na $141 \mathrm{mEq} / \mathrm{L}$ \\
K $5.3 \mathrm{mEq} / \mathrm{L}$ \\
Cl $103 \mathrm{mEq} / \mathrm{L}$ \\
Ca $9.5 \mathrm{mg} / \mathrm{dL}$ \\
CCa $10.2 \mathrm{mg} / \mathrm{dL}$ \\
P $5.5 \mathrm{mg} / \mathrm{dL}$ \\
Serum iron $88 \mu \mathrm{g} / \mathrm{dL}$ \\
TIBC $210 \mu \mathrm{g} / \mathrm{dL}$ \\
TSAT $42 \%$ \\
Ferritin $68.0 \mathrm{ng} / \mathrm{mL}$ \\
Intact PTH $1150 \mathrm{pg} / \mathrm{mL}$ \\
\hline
\end{tabular}

6 months of treatment, her intact PTH (iPTH) level and her serum calculated calcium (CCa) level decreased from 1150 to $283 \mathrm{pg} / \mathrm{mL}$ and from 10.2 to $9.9 \mathrm{mg} / \mathrm{dL}$, respectively (Fig. 1). Surprisingly, her $\mathrm{Hb}$ level was $12.9 \mathrm{~g} / \mathrm{dL}$ without ESA (Fig. 2). Serum alkaline phosphatase (AlP) level increased after the start of etelcalcetide and then decreased to $205 \mathrm{U} / \mathrm{L}$ after 6 months. The percentage of transferrin saturation (TSAT) gradually declined from 42 to $29 \%$ after 3 months and to $23 \%$ after 6 months. Iron had never been administered in the previous year and was never administered during this observation period either. ESA preparation had been administered at least once a month during the previous year. Her serum Alb level was between 3.3 and $3.4 \mathrm{~g} / \mathrm{dL}$ during the observation period. Her nutrition condition was stable. Neither fever nor leukocytosis was observed for 6 months, during treatment with etelcalcetide.

\section{Discussion}

Basically, this patient had three detectable parathyroid glands and high serum concentrations of PTH. Conventionally, these findings are indication of parathyroidectomy. In general, Japanese dialysis patients are of old age, are under dialysis for a long period, and present various complications, including cardiovascular diseases. Therefore, their medical conditions are not favorable for parathyroidectomy. Because this patient presented ophthalmologic and cardiac pathologies, she rejected parathyroidectomy, and her serum concentration of PTH continued to increase. After 6 months on etelcalcetide therapy, her PTH markedly decreased. This result suggested etelcalcetide had a strong suppressive effect on PTH excretion. Besides, etelcalcetide also reduced the serum level of calcium. These results suggested that etelcalcetide had a stronger calcium-decreasing effect than cinacalcet [5]. Cinacalcet and etelcalcetide are thought to have a similar mechanism of action in terms of their specific action in the parathyroid glands and suppression of PTH. The clinically different point is that etelcalcetide has a strong calcium-lowering effect compared to cinacalcet. Use of etelcalcetide can be expected to increase the use of vitamin $\mathrm{D}$ preparation as serum calcium-decreasing agent. It is known that $2 \mathrm{HPT}$ is associated with high bone turnover and leads to a decrease of bone mass and bone strength. Unfortunately, we did not measure bone metabolic markers. However, serum AlP level increased just after the etelcalcetide injection and then decreased to a level below the baseline value. Such AlP variation is very similar to that found in a previously reported research and which was associated with improved bone metabolic markers [6]. Our treatment regimen may contribute to suppress bone turnover. We were able to increase the dose of maxacalcitol because of this calcium-decreasing effect of etelcalcetide. Indeed, marked hypercalcemia was seen with maxacalcitol $10 \mu \mathrm{g}$ three times per week. In our patient, serum $\mathrm{CCa}$ was persistently about $10 \mathrm{mg} / \mathrm{dL}$. Thus, etelcalcetide allowed us to easily use and increase the dose of vitamin D. The patient had been administered ESA by injection for renal anemia during the previous year. However, after etelcalcetide was started, she did not receive ESA therapy, and during 6 months, her $\mathrm{Hb}$ level was stable at $12 \mathrm{~g} / \mathrm{dL}$. The dialysis conditions were not changed during this treatment period. Even though iron supplementation was not done, her anemia improved. It is also suggested that the use of iron may improve anemia during this time as TSAT also declines. This result may suggest that a decrease of PTH improves ESA resistance. However, from the fact that the $\mathrm{Hb}$ value is maintained high by the ESA 


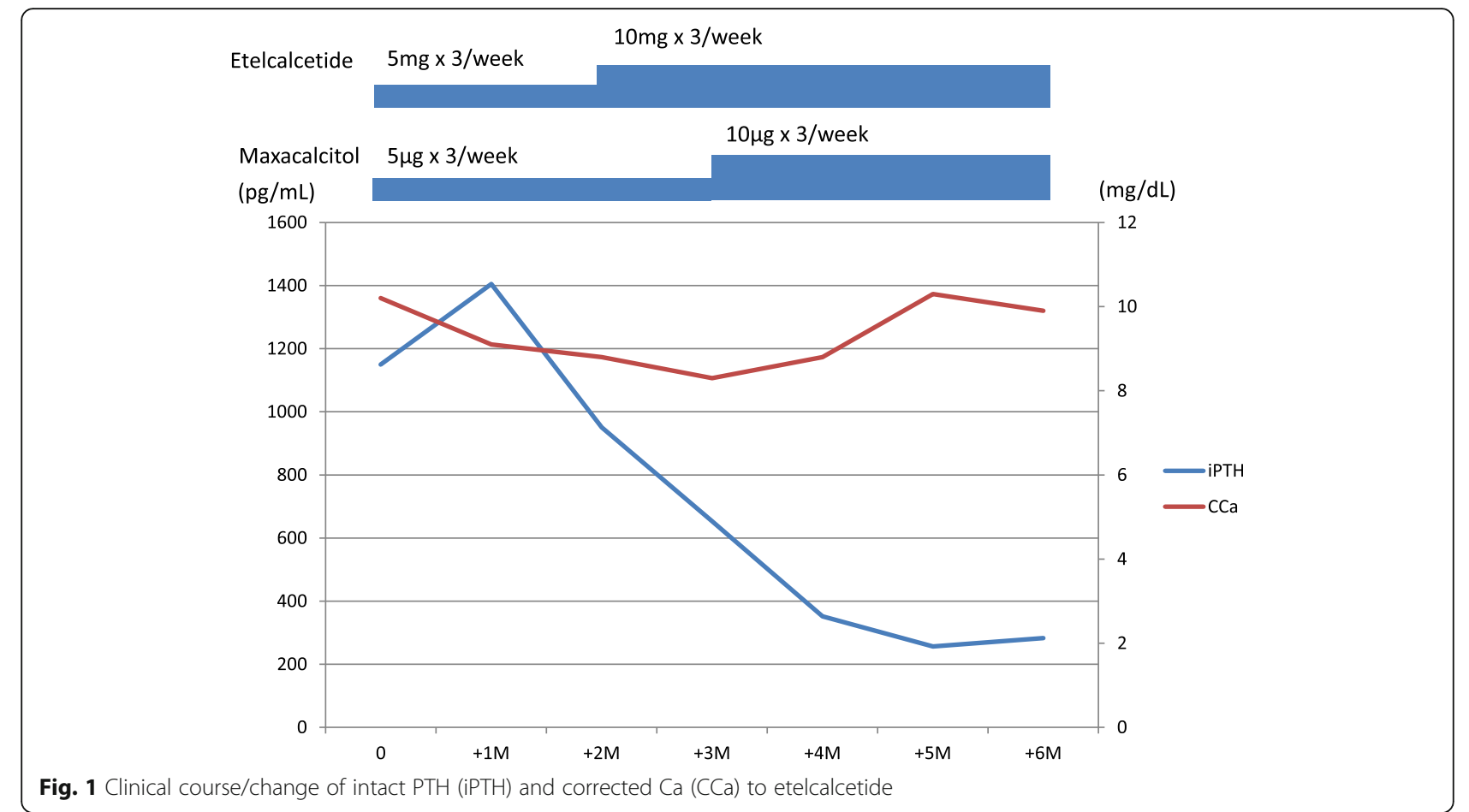

preparation administered prior to the start of etelcalcetide administration, it is not always possible to deny the long-term effects of the ESA preparation. In previous papers, it was reported that the control of PTH initially required a dose of erythropoietin that was decreased after parathyroidectomy [7], that vitamin D injection therapy corrected renal anemia [2], and that cinacalcet decreased ESA use [4]. In the past, we reported that cinacalcet improved not only severe 2HPT (iPTH 895 $\mathrm{pg} / \mathrm{mL}$ ), but also anemia in another patient. However, that patient did not have parathyroid nodules [3]. It is known that nodular parathyroid glands do not respond

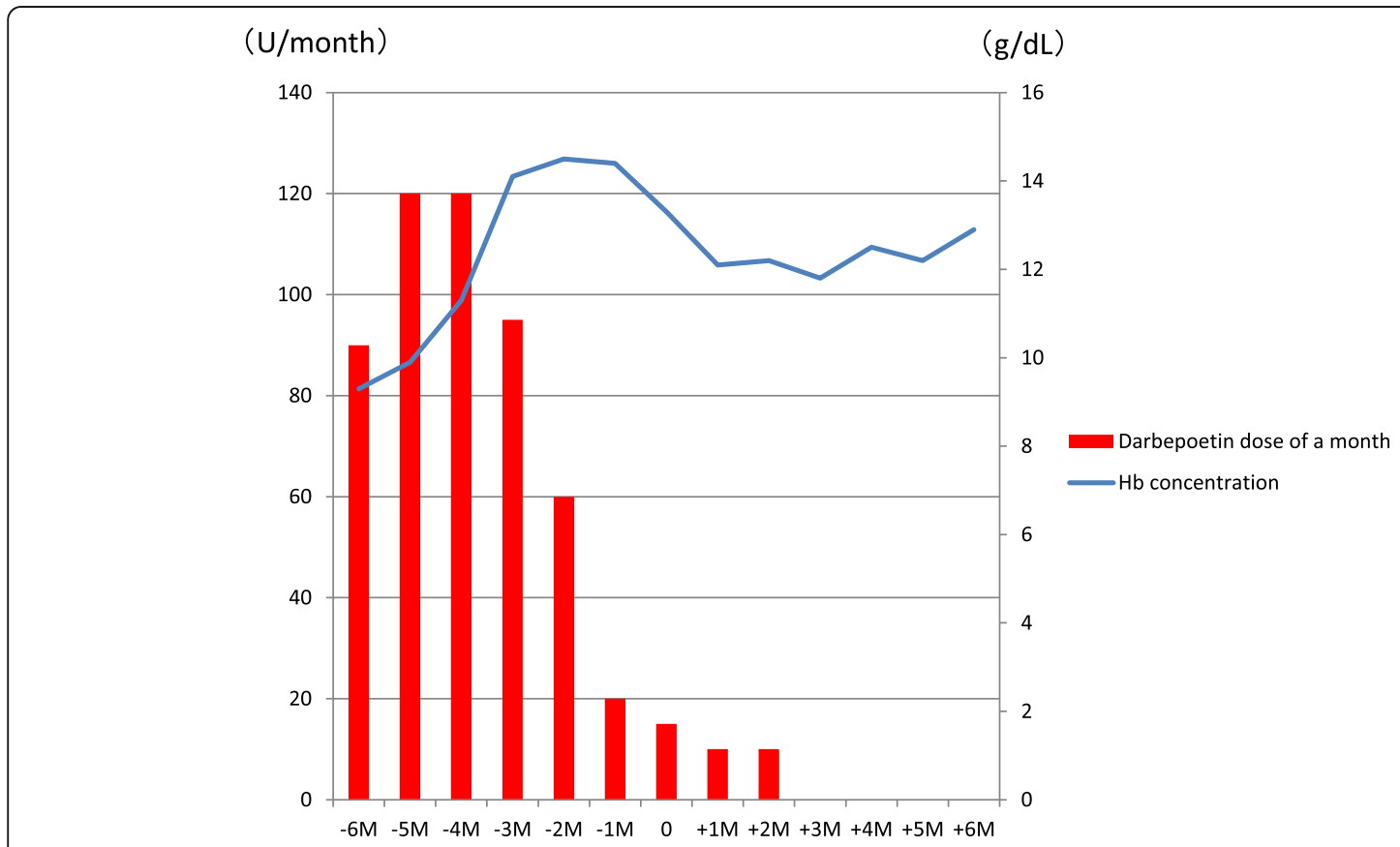

Fig. 2 Hemoglobin concentration and the amount of darbepoetin after a month on etelcalcetide medication 
to medical therapy [8]. Surprisingly, the present patient had a very high serum concentration of iPTH and three nodular parathyroid glands. Etelcalcetide may improve nodular parathyroid glands. Etelcalcetide is one of the strongest suppressive therapies for $2 \mathrm{HPT}$. The frequency of parathyroidectomy for $2 \mathrm{HPT}$ was markedly decreased by use of cinacalcet [9]. We think that in the future, the rate of parathyroidectomy will decrease even further by use of etelcalcetide. We have described a case of severe 2HPT that was successfully treated using etelcalcetide. This drug was not only effective for controlling $2 \mathrm{HPT}$ but also to restore renal anemia. As etelcalcetide is an injectable preparation, it has good compliance.

\section{Mini review}

\section{Improvement of renal anemia by PTH control Parathyroidectomy}

Parathyroidectomy (PTX) was the most reliable treatment for 2HPT before the use of vitamin D injection therapy. After PTX, the serum level of PTH markedly decreases, and it is reported that, as a result, endogenous erythropoietin increases and the dose of erythropoietin can be reduced [1, 7, 10-12]. It is known that severe 2HPT causes bone marrow fibrosis. It is thought that induction of erythropoietin is decreased by bone marrow fibrosis. Indeed, the percentages of osteoclast surface area, bone marrow fibrosis area, and eroded surface area were found to be higher in hemodialysis patients who showed a poor response to erythropoietin. Besides, those patients had higher level of PTH [13]. Consequently, it is thought that repair of bone marrow fibrosis via a decrease of PTH by PTX restores erythropoiesis in the bone marrow.

\section{Vitamin D therapy (Table 2)}

Vitamin D therapy was the only medical treatment for 2HPT before the advent of calcimimetics. Control of PTH by vitamin D contributes to improve renal anemia. It was reported that the decrease of PTH by alfacalcidol had resulted in an increase of $\mathrm{Hb}$ blood concentration [14]. Other vitamin D preparations, for example, intravenous calcitriol and paricalcitol, also normalize $\mathrm{Hb}$ concentration leading to a reduction of the required ESA dose $[2,15,16]$. Amelioration of osteitis fibrosa via the decrease of PTH with vitamin D medication may start to happen after around 3 months of treatment. However, these findings are supported by only a small number of studies. Vitamin D is also thought to directly improve renal anemia. It is reported that low levels of $25(\mathrm{OH}) \mathrm{D}$ are associated with lower hemoglobin concentrations [17]. And each of these associations was found to be independent of multiple potential factors-gender, reninangiotensin inhibitors, and inflammatory factors in no dialysis patients with chronic kidney disease [18]. There are also studies indicating a correlation between vitamin $\mathrm{D}$ deficiency and anemia and have suggested that a 25-OHD level of $<30 \mathrm{ng} / \mathrm{mL}$ is a risk factor for anemia [19]. These results imply that vitamin D contributes to ameliorate anemia in two ways, namely, through repair of osteitis fibrosa by decreasing the level of PTH and by direct stimulation of the proliferation of erythrocytes in the bone marrow.

\section{Calcimimetics (Table 3)}

Calcimimetics is the most recent treatment for $2 \mathrm{HPT}$. Currently in Japan, we can use three kinds of calcimimetics. Cinacalcet is the first calcimimetic that became available in Japan. The characteristics of cinacalcet are that in addition to a strong PTH lowering effect, it also decreases the levels of calcium and phosphate [20]. Amelioration of renal anemia by cinacalcet was reported in the form of an increase in $\mathrm{Hb}$ concentration and a decrease of the required dose of ESA [21, 22]. However, these two observational studies involved a small number of patients. The effect of cinacalcet in patients with renal anemia is thought to be due only to its PTH-lowering effect at present. Fusaro et al. noted that the dose of ESA could be decreased in patients treated with cinacalcet, but not in those treated with paricalcitol. This study has the following two problems. The level of PTH was suppressed much strongly in the cinacalcet group than in the paricalcitol group, and they evaluated only a very small number of patients. Although there was no significant difference between the two groups, it should be noted that in the paricalcitol group, the $\mathrm{Hb}$ concentration increased by $0.5 \mathrm{~g} / \mathrm{dL}$. This result cannot deny the $\mathrm{Hb}$ rising effect of paricalcitol [23]. Tanaka et al. performed a study in which they used data from Japanese hemodialysis patients with 2HPT. They selected patients with a $\mathrm{Hb}$ level of more than $10 \mathrm{~g} / \mathrm{dL}$. There were 1337 cinacalcet users and 1864 non-users. The results of this study showed that cinacalcet could be expected to improve renal anemia. Important doubts remained in this study regarding the effect of cinacalcet on renal anemia as vitamin $\mathrm{D}$ was administered to many patients. They reported that $1162(86.9 \%)$ patients in the cinacalcet group had taken vitamin D formulations [4]. It is also undeniable that the reduction of PTH by cinacalcet may enhance the action of vitamin D on bone. Vitamin D has also been used in many patients in other studies. Etelcalcetide and evocalcet have never been reported to date for the improvement of renal anemia, but an effect similar to that of cinacalcet can be expected. Etelcalcetide has a stronger calcium-lowering effect than cinacalcet [5]. As a result, the dose of a vitamin D preparation can also be increased, so that besides its powerful PTH lowering effect, a renal anemia-improving effect can be expected. 


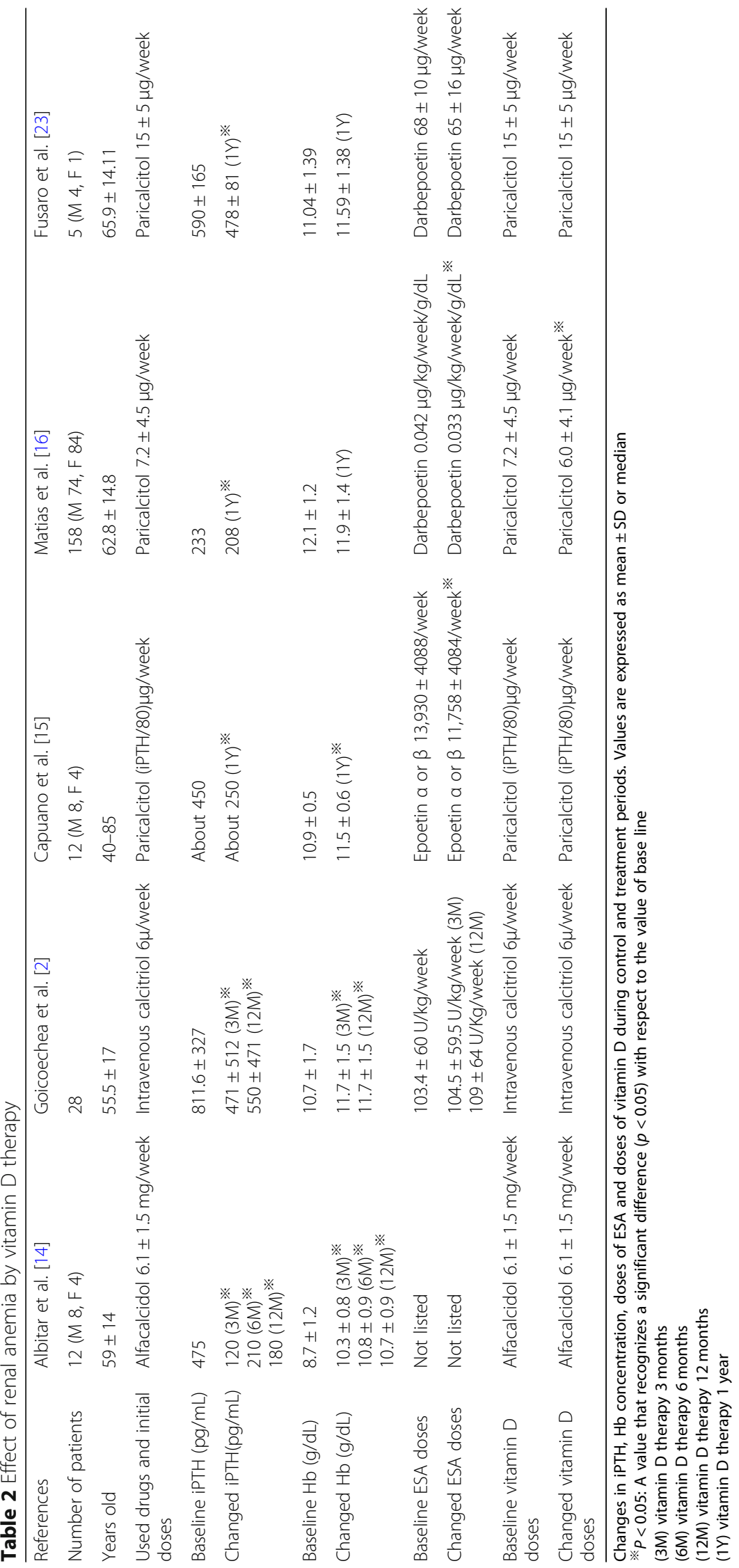


Table 3 Effect of renal anemia by cinacalcet therapy

\begin{tabular}{|c|c|c|c|c|}
\hline References & Viana et al. [21] & Battistella et al. [22] & Fusaro et al. [23] & Tanaka M et al. [4] \\
\hline Number of patients & $28(\mathrm{M} \mathrm{12}, \mathrm{F} \mathrm{16})$ & $\begin{array}{l}40 \text { (M 21, F 19) } \\
14 \text { PD } \\
18 \text { HD } \\
8 \text { over-night HD }\end{array}$ & $5(\mathrm{M} \mathrm{3}, \mathrm{F} 2)$ & 1337 ( M 800, F 537) \\
\hline Years old & Not listed & $54.6 \pm 14.2$ & $65.9 \pm 14.11$ & $58.88 \pm 11.78$ \\
\hline Used drugs and initial doses & Cinacalcet 30 mg/day & Cinacalcet 30 mg/day & $\begin{array}{l}\text { Cinacalcet } 212.6 \pm 60 \text { mg/ } \\
\text { week }\end{array}$ & Cinacalcet dose unknown \\
\hline Baseline iPTH (pg/mL) & $716.9 \pm 471.6$ & $198(153,248) \mathrm{pmol} / \mathrm{L}$ & $605 \pm 150$ & $340.00(223.00-506.60)$ \\
\hline Changed PTH (pg/mL) & $307 \pm 220.3(1 Y)^{*}$ & $\begin{array}{l}124(79,178)(3 \mathrm{M}) \\
116(64,180)(6 \mathrm{M}) \\
66(42-136)(12 \mathrm{M})^{*}\end{array}$ & $405.11 \pm 50(1 Y)^{*}$ & Not listed \\
\hline Baseline $\mathrm{Hb}(\mathrm{g} / \mathrm{dL})$ & $11.88 \pm 0.75$ & $11.6 \pm 1.3$ & $11.24 \pm 1.31$ & $10.65 \pm 1.09$ \\
\hline Changed Hb (g/dL) & $12.29 \pm 0.98(1 Y)^{*}$ & $\begin{array}{l}11.8 \pm 14(3 \mathrm{M}) \\
12.1 \pm 12(6 \mathrm{M}) \\
11.6 \pm 1.3(12 \mathrm{M})\end{array}$ & $12 \pm 1.19(1 Y)$ & $\begin{array}{l}\text { Initial concentrationx } 1.1 \\
(6 \mathrm{M})^{※}\end{array}$ \\
\hline Baseline ESA doses & $\begin{array}{l}\text { Darbepoetin } 0.042 \mu \mathrm{g} / \mathrm{kg} / \\
\text { week } / \mathrm{g} / \mathrm{dL}\end{array}$ & Darbepoetin $40(20,60) /$ week & $\begin{array}{l}\text { Darbepoetin } 70 \pm 26 \mu \mathrm{g} / \\
\text { week }\end{array}$ & Not listed \\
\hline Changed ESA doses & $\begin{array}{l}\text { Darbepoetin } 0.033 \mu \mathrm{g} / \mathrm{kg} / \\
\text { week/g/dL }\end{array}$ & $\begin{array}{l}30(20,60)(3 \mathrm{M}) \\
30(14,65)(6 \mathrm{M}) \\
24(20,56)(12 \mathrm{M}) *\end{array}$ & $\begin{array}{l}\text { Darbepoetin } 48 \pm 24 \mu \mathrm{g} / \\
\text { week* }\end{array}$ & Not listed \\
\hline Baseline vitamin D doses & Paricalcitol $7.2 \pm 4.5 \mu \mathrm{g} /$ week & Calcitriol $0.125 \mu \mathrm{g} /$ day & Not listed & Not listed \\
\hline Changed vitamin D doses & Paricalcitol $6.0 \pm 4.1 \mu \mathrm{g} /$ week $^{*}$ & Calcitriol $0.25 \mu \mathrm{g} /$ day & Not listed & Not listed \\
\hline
\end{tabular}

Changes in $\mathrm{PPTH}, \mathrm{Hb}$ concentration, doses of ESA, and doses of vitamin D during control and treatment periods

${ }^{*} P<0.05$ : A value that recognizes a significant difference $(p<0.05)$ with respect to the value of base line

(3 M) cinacalcet therapy 3 months

$(6 \mathrm{M})$ cinacalcet therapy 6 months

(12 M) cinacalcet therapy 6 months

(1Y) cinacalcet therapy 1 year

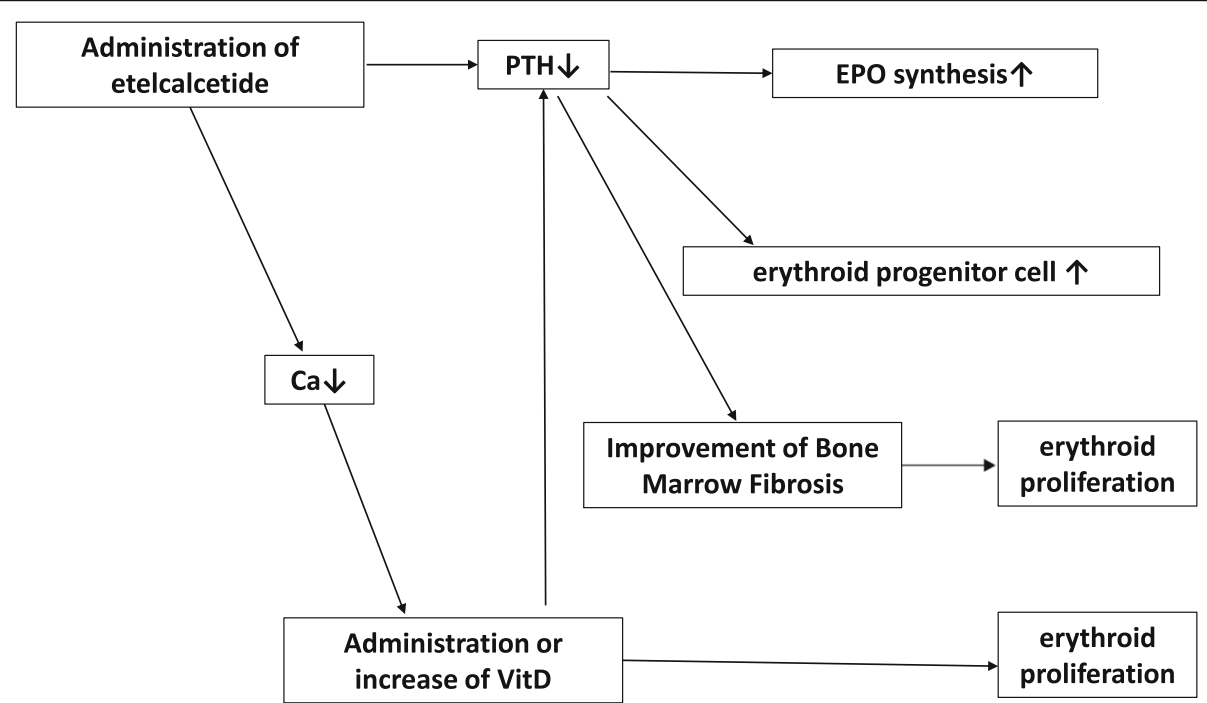

Fig. 3 Mechanism of renal anemia improvement by etelcalcetide. It is mainly thought that one is erythropoietin synthesis, increase of erythroid progenitor cells and improvement of bone marrow fibrosis, and another is erythroid proliferation induced by administration or increase of vitamin D 


\section{Conclusions of this mini review}

Improvement of $2 \mathrm{HPT}$ by various treatments (parathyroidectomy, vitamin $\mathrm{D}$ therapy, and cinacalcet therapy) is thought to improve renal anemia via erythropoietin synthesis and increase of erythroid progenitor cells by direct effect of decrease of PTH synthesis and an improvement of osteitis fibrosa. Apart from that, it is also suggested that vitamin D may improve renal anemia (Fig. 3). These findings are based on only a few studies involving limited number of patients; therefore, large-scale prospective studies will be necessary in the near future to confirm these findings.

\section{Abbreviations}

2HPT: Secondary hyperparathyroidism; CCa: Calculating calcium; ESA: Erythropoietin-stimulating agent; Hb: Hemoglobin; iPTH: Intact PTH; PTH: Parathyroid hormone

\section{Acknowledgements}

Not applicable.

\section{Funding}

The authors declare that there is no funding related to this manuscript.

\section{Availability of data and materials}

The data and materials were all included in the manuscript.

\section{Authors' contributions}

YO, TN, and MO took care of this patient. MO decided her treatment. YO prepared this manuscript. All authors read and approved the final manuscript.

\section{Ethics approval and consent to participate}

This article does not contain any studies with human participants or animals performed by any of the authors. Informed consent was obtained from a participant included in this study.

\section{Competing interests}

The authors declare that they have no competing of interests.

\section{Publisher's Note}

Springer Nature remains neutral with regard to jurisdictional claims in published maps and institutional affiliations.

\section{Author details}

${ }^{1}$ Kawasaki Medical School, General Internal Medicine 3, 2-6-1, Nakasange, Kita-ku, Okayama 700-8505, Japan. ${ }^{2}$ Saiseikai Imabari Hospital, 7-1-6, kitamura, Imabari City 799-1592, Japan.

Received: 24 September 2018 Accepted: 11 April 2019

Published online: 29 April 2019

\section{References}

1. Goicoechea M, Gomez-Campdera F, Polo JR, Tejedor A, Ruiz MA, Vazquez I, et al. Secondary hyperparathyroidism as cause of resistance to treatment with erythropoietin: effect of parathyroidectomy. Clin Nephrol. 1996;45(6): 420-1.

2. Goicoechea M, Vazquez Ml, Ruiz MA, Gomez-Campdera F, Perez-Garcia R, Valderrabano F. Intravenous calcitriol improves anaemia and reduces the need for erythropoietin in haemodialysis patients. Nephron. 1998;78(1):23-7.

3. Oshiro Y, Tanaka H, Okimoto N. A patient undergoing chronic dialysis whose renal anemia was successfully corrected by treatment with cinacalcet. Clin Exp Nephrol. 2011:15(4):607-10.

4. Tanaka M, Yoshida K, Fukuma S, Ito K, Matsushita K, Fukagawa M, et al Effects of secondary hyperparathyroidism treatment on improvement in anemia: results from the MBD-5D study. PLoS One. 2016;11(10):e0164865.

5. Block GA, Bushinsky DA, Cheng S, Cunningham J, Dehmel B, Drueke TB, et al. Effect of etelcalcetide vs cinacalcet on serum parathyroid hormone in patients receiving hemodialysis with secondary hyperparathyroidism: a randomized clinical trial. Jama. 2017;317(2):156-64.

6. Fukagawa M, Yokoyama K, Shigematsu T, Akiba T, Fujii A, Kuramoto T, et al. A phase 3, multicentre, randomized, double-blind, placebo-controlled, parallel-group study to evaluate the efficacy and safety of etelcalcetide (ONO-5163/AMG 416), a novel intravenous calcimimetic, for secondary hyperparathyroidism in Japanese haemodialysis patients. Nephrol Dial Transplant. 2017;32(10):1723-30.

7. Barbour GL. Effect of parathyroidectomy on anemia in chronic renal failure. Arch Intern Med. 1979;139(8):889-91.

8. Fukagawa M, Kitaoka M, Inazawa T, Kurokawa K. Imaging of the parathyroid in chronic renal failure: diagnostic and therapeutic aspects. Curr Opin Nephrol Hypertens. 1997;6(4):349-55.

9. Tominaga Y, Kakuta T, Yasunaga C, Nakamura M, Kadokura Y, Tahara H. Evaluation of parathyroidectomy for secondary and tertiary hyperparathyroidism by the Parathyroid Surgeons' Society of Japan. Ther Apher Dial. 2016;20(1):6-11.

10. Shasha SM, Better OS, Winaver J, Chaimovitz C, Barzilai A, Erlik D. Improvement in the anemia of hemodialyzed patients following subtotal parathyroidectomy. Evidence for the role of secondary hyperparathyroidism in the etiology of the anemia of chronic renal failure. Isr J Med Sci. 1978; 14(3):328-32.

11. Urena P, Eckardt KU, Sarfati E, Zingraff J, Zins B, Roullet JB, et al. Serum erythropoietin and erythropoiesis in primary and secondary hyperparathyroidism: effect of parathyroidectomy. Nephron. 1991;59(3):384-93.

12. Trunzo JA, McHenry CR, Schulak JA, Wilhelm SM. Effect of parathyroidectomy on anemia and erythropoietin dosing in end-stage renal disease patients with hyperparathyroidism. Surgery. 2008;144(6):915-8 discussion 919.

13. Rao DS, Shih MS, Mohini R. Effect of serum parathyroid hormone and bone marrow fibrosis on the response to erythropoietin in uremia. N Engl J Med. 1993;328(3):171-5.

14. Albitar S, Genin R, Fen-Chong M, Serveaux MO, Schohn D, Chuet C. Highdose alfacalcidol improves anaemia in patients on haemodialysis. Nephrol Dial Transplant. 1997;12(3):514-8.

15. Capuano A, Serio V, Pota A, Memoli B, Andreucci VE. Beneficial effects of better control of secondary hyperparathyroidism with paricalcitol in chronic dialysis patients. J Nephrol. 2009;22(1):59-68.

16. Matias PJ, Jorge C, Ferreira C, Borges M, Aires I, Amaral T, et al. Cholecalciferol supplementation in hemodialysis patients: effects on mineral metabolism, inflammation, and cardiac dimension parameters. Clin J Am Soc Nephrol. 2010;5(5):905-11.

17. Kendrick J, Targher G, Smits G, Chonchol M. 25-Hydroxyvitamin D deficiency and inflammation and their association with hemoglobin levels in chronic kidney disease. Am J Nephrol. 2009;30(1):64-72.

18. Patel NM, Gutierrez OM, Andress DL, Coyne DW, Levin A, Wolf M. Vitamin D deficiency and anemia in early chronic kidney disease. Kidney Int. 2010; 77(8):715-20.

19. Sim JJ, Lac PT, Liu IL, Meguerditchian SO, Kumar VA, Kujubu DA, et al. Vitamin D deficiency and anemia: a cross-sectional study. Ann Hematol. 2010;89(5):447-52

20. Block GA, Martin KJ, de Francisco AL, Turner SA, Avram MM, Suranyi MG, et al. Cinacalcet for secondary hyperparathyroidism in patients receiving hemodialysis. N Engl J Med. 2004;350(15):1516-25.

21. Viana H, Lobos VA, Resina C, Lopes RJ, Guerra A, Costa FT, et al. Treatment of secondary hyperparathyroidism with cinacalcet is associated with an increase in haemoglobin level. Port J Nephrol Hypert. 2007;21(3):225-9.

22. Battistella M, Richardson RM, Bargman JM, Chan CT. Improved parathyroid hormone control by cinacalcet is associated with reduction in darbepoetin requirement in patients with end-stage renal disease. Clin Nephrol. 2011; 76(2):99-103.

23. Fusaro M, D’Angelo A, Naso A, Frigo AC, Miozzo D, Gallieni M, et al. Treatment with calcimimetic (cinacalcet) alters epoetin dosage requirements in dialysis patients: preliminary report. Ren Fail. 2011;33(7):732-5. 